\title{
Improving Learning Effectiveness- Some Aspects Shouldn't Be Ignored in Mathematics Teaching
}

\author{
Yuqing Yan \\ Columbus Humanities Arts and Technology Academy, ACCEL Schools, Ohio, USA, 43229
}

\begin{abstract}
There are abundant educational resources in the USA, but the performance of math education in primary and secondary schools is not so well, and has lagged behind some Asian countries including developing countries. Among many reasons, the crucial reasons are how teachers teach, how students learn, and the level of school teaching management. This paper focuses on how teachers teach in five aspects, particularly emphasizes on how to improve students' retention and understanding of knowledge, and to enhance learning and thinking abilities. It points out that teachers should constantly remind students to maintain basic facts, create assignments for students by combining regular methods with the strategies of interleaved and spaced practice, build connections among knowledge, pay attention to improve students' ability of problem-solving, and use some complementary approaches to generate students' interest, participation, memory and concentration in math. And also it mentions that self-discipline, persistence and confidence are significant in prompting learning efficiency. In addition, some suggestions are put forward for school education management in supporting teaching and learning.
\end{abstract}

Keywords: memory, understanding, practice, procedure, connection, problem-solving
*Correspondence to Author: Yuqing Yan

Columbus Humanities Arts and Technology Academy, ACCEL Schools, Ohio, USA, 43229

How to cite this article:

Yuqing Yan. Improving Learning Effectiveness- Some Aspects Shouldn't Be Ignored in Mathematics Teaching. American Journal of Educational Research and Reviews, 2020,5:74.

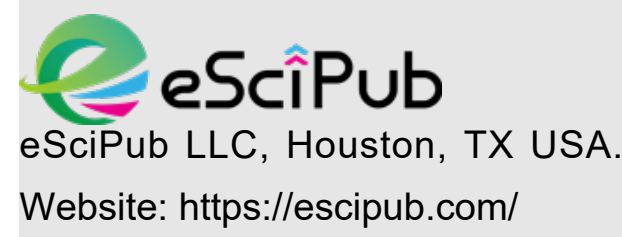




\section{Introduction}

Mathematics is the most international of all curriculum subjects, its importance is never reduced with the wide-spread application of computer science and technology. Mathematical competence influences decision making in all aspects of life ${ }^{1}$. For a nation, the number of mathematical talents is a symbol of science, technology and economic competitiveness and growth. For individuals, their good mathematical abilities will be beneficial for them continuing learning different types of knowledge and skills, increasing career opportunities and success.

Mathematics is so important, but many students struggle with math learning and easily feel frustrated. This is the main reason that effective teaching and learning in math have been concerned by cognitive, educational psychologists and educators today and in the past 2,3,4,5,6.

Although America leads the world in science, technology and higher education, in K-12 education, American students are less proficient in mathematics, science, and reading than their peers in other countries ${ }^{5,6}$. There are many affecting factors ${ }^{1-6}$ to cause this, but the most important one is effective teaching, which alone can lead to effective learning. While teachers transmit knowledge to students, more importantly, teach them how to learn ${ }^{6}$. This is the ultimate goal of school education. And teachers are the single most important resource for developing students' mathematical identities. By attending to the differing needs that derive from home environments, languages, capabilities, and perspectives, teachers allow students to develop a positive attitude to mathematics. A positive attitude raises comfort levels and gives students greater confidence in their capacity to learn and to make sense of mathematics ${ }^{1}$.
To generate students' enthusiasm, enhance students' five strands of mathematical proficiency (Conceptual understanding, Procedural fluency, Strategic competence, Adaptive reasoning, Productive disposition) ${ }^{7}$, teachers have the responsibility to keep in mind and to make effort to help students.

This paper is organized as follows: Section 2 mentions some phenomena that showed poor math skills in some 5th and 6th graders. Section 3 presents five main aspects that math teachers need to pay attention while teaching in order to solid students' math foundation and to improve their learning and thinking abilities. Section 4 provides some suggestions for teaching management. Section 5 makes a conclusion.

\section{Students' Math Skills: Some Phenomena}

In a school, almost all fifth and sixth graders still counted in fingers to calculate within 20 addition and subtraction, used repeated addition to do multiplication, did not know how to borrow 1 from hundreds place or thousands place to do the subtraction for ones place, they even could not understand and did not know how to do first grade subtraction word problems. Their math base was very poor, it's totally out of keeping with their age and grade. Another phenomenon was when they used the Box-it method to do subtraction, they put zero in front of the difference. This showed they were not taught a standard way to express numbers and calculation procedures.

Even though this very poor performance in math and reading is not a popular phenomenon in elementary and middle schools of America, it exists, it needs to be changed and it can be changed although there is a long way to go. Schools, teachers, families and governments need to work together to change it. But, first of all, the responsibilities of schools and teachers 
are essential. Schools are the place where the intelligence is enlightened and the learning passion is inspired. Teachers are sowers and cultivators, the performance of students are the harvests. Teachers are guiding lights, lighting up students' learning way. Every student is like a white canvas, teachers' teaching just likes drawing pictures on it. So, between how teachers teach and how students learn, there is a definite connection. Hence, to change the situation of poor performance in learning, it must start from the teachers.

\section{Some Aspects Shouldn't Be Neglected in Mathematics Teaching}

Teachers should not just focus on what students should learn, but also should consider how they learn 6 . How to learn is a matter of learning skills - a capacity to learn. From the perspective of lifelong learning, the instruction of learning experiences and skills is more important than simply transmitting knowledge to students. If students have learning capacity, they will feel more confident in learning and to overcome the difficulties they encounter. Learning skills include how to memorize basic facts (e.g. fact family, times table), how to understand concepts and principles, and how to apply knowledge to solve problems, which are the purposes of learning and three main elements that could help students better master knowledge.

What's more, as a rigorous science, the rigor of mathematics is presented by the precise expression and logic rationality of operational statements and inference procedures when solving problems. Mathematical language requires the precise expressions that are embodied in logical procedures. When teachers instruct concepts, methods and procedures, the standardization and rigor of mathematical expressions should not be neglected. Standard and normative expressions of math language can help students to form their mathematical thinking patterns.

And it is acknowledged that memory is the forerunner of any effective learning. Without memory for concepts and basic facts, understanding will be out of questions, further learning will lack a solid foundation. So, for being effective teachers, they should not merely consider what to teach, but should concern how students can understand and remember, which will be the premise of letting students become fast learners.

\subsection{Remind Students to Memorize Important Contents}

High mathematics skills are not required to memorize all teaching contents for being able to retrieve knowledge from memory, but require them to remember basic concepts, principles and facts (e.g., addition chart within 20, multiplication chart) ${ }^{5}$. But many teachers often don't remind their students to use important principles to think and to do practices. For second graders, they need to practice mental calculation within 20 based on fact family, not just use a number line or 100 charts or counting fingers - less technical methods to get the results. For 4th graders, when they do addition or multiplication, except using fact family, they should be encouraged to use properties such as commutative property, associative property, distributive property, try to stop them counting fingers to do addition/subtraction within 20.

Teachers should have awareness that students' knowledge retention is important. Memorizing basic mathematical facts doesn't mean rote learning though that is needed especially before examinations. More often, understanding and memorizing are tangled up. In a harmonious scene of instruction students focus on learning and feel enjoyable. 
The retention of basic facts such as addition table within ten, subtraction table within 20, multiplication chart, will develop the fluency and automaticity of calculation. If students are not encouraged to consciously remember the basic facts, their learning efficiency can't be improved, thus the teacher's educational purpose can't be achieved. So, when teachers realize students' deficiencies in calculation skills and math bases, they should always remind them what knowledge they need to gain or regain and try to help them to enhance their math skills. For stimulating students to remember important facts, a method is to compare the calculation efficiencies such as accuracy and speed among different techniques.

Students' concentration is important to improve their unconscious retention efficiency. One method is to suggest students make class notes and take it home to review, to reappear what teachers taught. Even first graders should be suggested to make notes. They can draw some lines and irregular pictures instead of words and sentences that they may not know how to write. Taking notes is a good learning habit that teachers should always encourage students to do. Teachers can also suggest students make flash cards at home by using some waste paper boxes (e.g., candy boxes, cracker boxes). This is a good way to develop students' self learning ability by willingly writing important facts on selfmade flash cards, and at the same time it can improve students' practical ability and economical sense.

\subsection{Embracing Integrated Practice Methods to Improve Teaching and Learning Efficacy}

Mathematics learning consists of two parts: principles (concepts, facts, procedures) and practice. The purpose of practice is to improve learners' conceptual understanding, computational fluency and problem solving skills. The effect of practice and the scores of tests are the key measurements of learning efficiency and mathematics skills.

There are different strategies to do practices. The very popular so called blocked practice method, is an approach with which the same strategy is used in practice each time, no strategy selection would be necessary ${ }^{4}$. Interleaved practice is a learning approach where different kinds of problems or the same problem solved by different strategies are arranged in a worksheet ${ }^{4,8}$. For example, for 4th graders, round numbers, add whole numbers, and multiply fractions by whole numbers can be organized together; or when doing multiplication, students are required to choose the right strategy from distributive property, area model, partial product, and regular method. A strategy means a procedure, formula or concept based on the problem itself ${ }^{4,8}$. Spaced practice means the same kinds of problems are arranged and spaced out over time, a given amount of practice is divided across multiple sessions ${ }^{5,9}$.

For students retaining knowledge and gradually building up their good math foundation and learning faith, teachers need to consciously adopt different instruments and apply effective teaching methods.

\subsubsection{Why interleaved and spaced practice methods are less used: the possible reasons}

Blocked practice, massed practice and overlearning are very prevailing in mathematics teaching and learning, yet interleaved practice and spaced practice are not extensively applied in the classroom. Massed practice means the problems relating to a given topic typically appear in the same practice sheets. As a practice strategy, overlearning means many students have mastered or basically mastered a skill and 
then still continue to practice the same skill at the same time period again and again ${ }^{9}$.

The blocked, massed practice and overlearning is more popular than the interleaved and spaced practice, the reasons could be:

\section{(1) Awareness}

Blocked, massed practice and overlearning are so prevalent in the past and at present, and easily operated that many teachers adopt them unconsciously. Especially when students are not fully stimulated or not enthusiastic in learning, teachers would usually spend more time in managing the classroom rather than doing regular teaching that can cause teachers to use easy practice strategies instead of integrated methods or use overlearning to try to improve students' mastery.

\section{(2) Weak foundation of math}

When students' math foundation is weak, interleaved practice will be a challenge to them.

(3) The tendency of textbooks and online learning aids

Most mathematics textbooks and quantities of online learning resources provide blocked, massed practice and overlearning and minimize distributed (interleaved and spaced) practice ${ }^{5}$. Only a few textbooks and practice books apply interleaved practice such as Saxon Math and Carson-Dellosa Weekly Practice: Math Workbook. This reality has misled teachers and prevented them from using interleaved practice and spaced practice.

\section{(4) Teaching management}

The advocates of the educational authorities will have a direct impact on teachers' teaching methodologies and effects. Too tight teaching schedules would cause teachers to be exhausted, affect their teaching efficiencies and the application of integrated teaching methods.
Although many researchers have been recommending applied distributed practice and spaced practice in mathematics ${ }^{4,5,9}$, to what extent that teachers should implement them should depend on the specific teaching contents and students. But the combination of massed practice and overlearning with interleaved and space practices are always recommended ${ }^{4}$. For students who have a weak foundation in mathematics, massed practice and overlearning should be more often applied and with a small part of interleaved practice and spacing out practice over a period of learning.

\subsubsection{The features and benefits of advanced practice methods in promoting mathematics teaching and learning}

Students would forget most of the knowledge within days of learning with regular methods such as blocked, massed. This phenomenon has become very common today and in the past 9 . This is a less effective method for retaining and understanding knowledge in comparing interleaved and spaced practice methods ${ }^{4,5,6,9}$. That is said that regular practice methods can't be better to improve the connection of knowledge and mental ability of students than to implement interleaved and spaced practice methods.

Research has shown that interleaved practice combined with spaced practice is more superior to blocked practice, massed practice and overlearning in many ways:

\section{(1) Enhancing memory}

Spaced practice can boost long-term retention and mastery of knowledge, but not massed practice and overlearning which can only raise automaticity and rote memory for the studied material but lack of connected and meaningful memories $5,8,9$

\section{(2) Effective learning}


Practice is more effective when spaced out over time, instead of massed or grouped together ${ }^{5}$. Interleaved practice outscores the blocked practice ${ }^{5,8}$. These benefits arise because interleaved practice provides students with an opportunity to learn how to choose an appropriate strategy (and learn what they can't do). In short, interleaved practice simply provides students with an opportunity to practice the very skill they are expected to learn 4 .

\section{(3) Time saving}

Spaced practice produces a large benefit with no requiring extra practice, but massed practice and overlearning takes up precious learning time, and produces less benefit ${ }^{6,9}$. Kang ${ }^{5}$ thought that spaced practice in comparison with massed practice could enhance the efficacy and efficiency of learning, avoid relearning, save learning time to move on further knowledge learning that can bring more benefits to students.

\section{(4) Improving understanding}

Regular practice methods combined with interleaved and spaced practice can produce better learning results. By the application of the interleaved and spaced, students are being able to independently think and get automaticity in choosing a right strategy and fluency in solving a problem and act flexibly with a topic or concept. That means students already acquire the knowledge understanding ${ }^{7}$. And, spaced practice helps knowledge retention so that students possess adequate prior knowledge to facilitate subsequent learning and comprehension ${ }^{5}$.

(5) Raising the abilities of knowledge differentiation and quick knowledge retrieval

Interleaved practice challenges students' knowledge understanding and reproduction that can gradually make students learn to differentiate various types of problems and corresponding knowledge as well as the association among different problems and knowledge. But blocked practice can't effectively help students clearly discriminate the problem types and know when to use which formula. And because spaced practice benefits retaining knowledge, when both work together that will finally be able to facilitate not only more accurate recall of knowledge but also quicker retrieval of essential data ${ }^{5}$.

\section{(6) Promoting problem-solving skills}

A good problem-solving ability depends on good knowledge retention and retrieval, and clear knowledge discrimination. Interleaved practice and spaced practice can help students to reach these purposes, consequently raise their problems solving skill and self-confidence. But with blocked practice, all the problems at each session are required only the same strategy to solve, the students' learning ability and problem solving skill can't be improved to the necessary level.

\section{(7) Feasible and cost-effective}

Interleaved practice and spaced practice are easily put into use. Rohrer et. al. argued that "Interleaved mathematics practice appears to be a feasible intervention....Classroom implementation would also seem to require relatively little effort from teachers because they need not alter their classroom lessons or the manner in which they solve a particular problem....The intervention would also presumably require little or no teacher training" ${ }^{4}$ and "requiring neither technology nor proprietary materials" ${ }^{8}$. Because spaced practice can make profit in learning, cause less time needed in the same content, which can lead to future savings such as students skip a grade but not stay down or their learning ability can be improved to a higher level to achieve future success ${ }^{5}$.

Because of the abundant benefits of applying interleaved and spaced practice methods, teachers need to give more thoughts about how to 
apply interleaved and spaced practice into practical classes.

\subsection{Emphasis on Building Connections among Knowledge}

Building connections among knowledge but not isolated them is the prerequisite to understand knowledge, to remember and recall knowledge, and also be able to enhance students' thinking and inferential capabilities. Understanding is a primary goal of mathematics teaching and learning although it is uneasy to achieve it due to some reasons ${ }^{9}$. One reason is students don't have sufficient learning time in school. Many teachers have to spend precious teaching times doing classroom management, students' precious learning time is invisibly deprived. Another reason is students don't spend enough time learning at home. The time students stay at home is more than two thirds of a year. If students can work hard at home, it will naturally improve students' learning ability and the command of knowledge. Even so, teachers should still try their best to let students understand what they learn as much as possible. The best way to achieve this goal is to emphasize the interconnectedness of knowledge.

\subsubsection{Holding a connective perspective while instructing and learning}

Effective teachers emphasize links between different mathematical ideas. The ability to make connections between apparently separate mathematical ideas is crucial for conceptual understanding, at the same time it can develop students' associative thinking. Stylianides et. al. ${ }^{10}$ thought that the image of effective teaching should be in supporting students to create interweaving connections among concepts, representations, methods, procedures, basic facts. And to make sense of a new concept or skill, students need to be able to connect it to their existing mathematical understandings, in a variety of ways. Tasks that require students to make multiple connections within and across topics help them appreciate the interconnectedness of different mathematical ideas and the relationships that exist between mathematics and real life. For example, for 4th grade, multiplication can be connected with repeated addition, array (rows and columns), equal groups, area model, estimation, partial product, commutative property, distributive property, associative property, identity property, division. If students can put all these things together and build the connections in their mind, that means they already understand and command these knowledge. Another example, for 1 st graders, although they can count from 0 to 100 continuously and quickly, they don't necessarily understand the relationship between consecutive whole numbers, that is, the fact that any whole number adds 1 will be the next number or any whole number minus 1 will be the previous number. When counting a whole number plus 1 such as $6+1$, they don't spontaneously establish relationships among 6 , $6+1$ and 7 , they count their fingers to get the result 7 , but don't use number sense to quickly get the result. So, before they can understand the fact, teachers should let them remember the fact: any whole number adds 1 will be the next number or any whole number minus 1 will be the previous number. Gradually, their number sense and understanding will be established, and more importantly, their intelligence will be developed.

\subsubsection{Applying a connective viewpoint while designing and doing practice}

Stylianides et. al. ${ }^{10}$ argued that the more number and strength of the connections, the more degree of understanding, and the more learning benefit that students will be beneficial to. Although interleaved practice doesn't require logical relationships among different kinds of https://escipub.com/american-journal-of-educational-research-and-reviews/ 
problems in a worksheet, it requires students to select the right strategy to solve a problem or the same problem solved by different strategies. To make interleaved practice more effective, a connective viewpoint should be applied in designing interleaved practice.

A scenario of using the view of connection is that teachers can select a few typical problems as examples to show the same problem solved by different strategies or one problem can be changed into different problems, which may play an important role in developing students' curiosities, critical thinking and cultivating their learning capacity. For example, when counting elapsed time, several strategies can be used which can connect the knowledge of one hour 60 minutes, number line, time decomposition, analog clock, 12 hour time format, AM, PM, 24 hour time format, addition, subtraction, multiplication. By using different strategies to calculate the elapsed time, students will have a better understanding about the elements of time, clock and their relationships.

\subsubsection{Constructing knowledge maps while reviewing}

Stress on connections among knowledge is not only in new knowledge presenting, not only in instructing examples and doing practice, but also in reviewing the contents they have learnt. Kang ${ }^{5}$ suggested that spaced review should be used as a regular teaching method. In limited teaching time, the feasibility of spaced review needs to do more experiments (of course, it is feasible for reviewing each unit when it is finished, but reviewing the same unit in different time, it seems impractical), but review itself is necessary. The principles of review are Consistency and Connectivity. Consistency means the mathematical expressions should be kept the same explanations and non divergence.
Connectivity means to connect different knowledge points with each other, not just simply conclude the knowledge learnt in the current unit otherwise this kind of review is ineffective 5 . When reviewing, current knowledge (concepts, methods, procedures, facts) should also be interwoven with other relevant knowledge, even other subjects when necessary, and a diagram/graph can be used to show the knowledge structure and relationship that will make the connections more concrete, pictorial and imaginable.

\subsection{Stress on Improving Students' Problem Solving Skills}

Understanding and remembering knowledge can improve students' ability to solve problems. Strong problem solving skills are reflected not only in the thinking patterns, not only in the correct selections of strategies, but also in the correct writing of procedures with normative mathematical language.

\subsubsection{Pay attention to problem solving efficiency}

The problem-solving skill is a very important metric to examine the effectiveness of teaching and learning. The efficiency of problem solving lies in the correct selection of strategies and the speed of solving problems (Given they can be correctly solved).

\section{(1) Improving problem solving efficiency: se- lecting correct strategies}

Being able to make a correct selection of strategies should be based on understanding and retention toward knowledge, also based on experiences and some thinking capacities such as judgement and observation. All of these qualities can be trained under interleaved and spaced practice with the emphasis of connections of knowledge. So teachers should create opportunities for students and encourage them to solve 
a problem with different strategies, and to make comparisons of the effectiveness among strategies. If students only rely on teachers to tell them how to do and what strategies to select, they can't learn math well, their math skills and learning abilities as well as mental faculties will be no way to be improved.

\section{(2) Improving problem solving efficiency: in- creasing speed}

To increase the speed of solving problems, on the one hand, students should be able to make the right decision in selecting strategies; on the other hand, they should be able to remember and recur basic facts, know how to use operational properties, be able to find similarities of the problems and to apply supplementary relationship when necessary, and interest in mental calculation.

In order to improve students' problem-solving speed, after they learn new facts or skills, teachers should carefully observe if they apply new methods to solve current problems but not use fingers or other low level techniques such as a number line, a 100 chart to reach solutions (but that doesn't mean they should not know how to use or forget these simple techniques). They should be always encouraged to use advanced methods because their math skills should be gradually prompted and the further learning needs advanced methods.

For enhancing students' operation speed, to avoid blind practicing, teachers should try to direct them to remember and understand the calculation procedures, and also point out the commonness or regularity that occur in different problems, which would raise students' attention to the procedures and help them increase their arithmetic skills. For examples, when 2 nd grade teachers illustrate these three additions: $219+727,292+187$ and $325+374$, they need to remind students to pay attention to $2+7$, which exists in all three problems. The benefit is students only need to calculate once $2+7$, instead they repeat counting their fingers for $2+7=9$ three times.

And, teachers should guide students to recognize the complementary relation and reverse relation. For example, for "make 10", 2 and 8 are mutually complementary because $2+8=8+2=10$. When students understand the "make 10" concept, they will easily build a connection between 0 and 10, 1 and 9, 2 and 8, etc. It will further the number sense of students. Similarly, when students understand the reverse relation and know how to use it, their learning and thinking abilities will be improved.

\subsubsection{Stress on using normative and rigorous mathematical language}

Mathematical proficiency lies in if students know how to use concise and comprehensive mathematical language to express their thoughts and procedures. But a common situation is many students don't know how to write their thoughts in a brief way or they don't have the habit of writing with mathematical language. When they solve a problem, they don't write a logical deduction process but instead by a number, the result. This phenomenon is very common especially under 6 th grade. The reason may be the types of problems are overdependent on multiple-choice and fills-up topics in computer paperless worksheets. It cannot be denied that this is the easiest way to provide students practices. But the side-effect is that the more students get used to the multiple-choice and fills-up topics, the less their mathematical ability gains. This can severely weaken students' ability of organization and expression with math language. Under such a reality, students' capability of solving problems is difficult to be enhanced. 
Mathematics is a rigorous science that is reflected by its normative and logical expressions and procedures. It is mandatory for students to command standard mathematics language as a basic requirement of their math quality. When students do their worksheets or tests, they ought to use normative mathematical language to express their thoughts and computational processes concisely, comprehensively and less redundantly, try not to write down any irrelevant notations such as arrows or circles or lines in the procedures, although these mnemonic characters would be help them to remember or understand the procedures, but they can write them in a draft paper yet not on a formal test paper. If they don't follow the instructions, their scores can't reach the high.

In order to improve students' ability of solving problems, they should be often reminded and required in correctly writing procedures with concise mathematical signs and expressions.

\section{(1) Using standard signs and expressions}

Being mathematically disciplined, students should be always guided to use standard expressions. If teachers try to make teaching more understandable by using some auxiliary tokens such as arrows, cross symbols while presenting new procedures, but later teachers must give an explanation about what are the standard usages and what they are required to do.

\section{(2) Avoiding overly relying on multiple choice and fill-in-the-blank questions}

Each worksheet that teachers prepare for students should contain at least one problem that needs to be solved by writing the procedure. After the worksheets were graded, when necessary, teachers should give feedback to students.

\section{(3) Provide the steps of problem-solving for the students}

Before the students really get the hang of the methods of correctly solving problems, they need to imitate the examples and procedures. So, for the steps of typical problems' solutions, teachers can print them on papers or put them online to let students have good guidance especially when students don't have textbooks provided.

\subsubsection{Learn from mistakes}

\section{(1) Feedback improves learning}

Teachers should let students realize that they are allowed to make mistakes, and encouraged to take risks, try new tools and strategies, which are good opportunities for them to learn ${ }^{7}$, they should not be defeated or mocked by making mistakes. And also teachers should give feedback to students to let them realize where and why they made mistakes. It will be beneficial for improving their understanding and retention of knowledge and problem solving skills. In addition, teachers should pay close attention to the same mistakes that most students make, which may reflect something wrong about the instructing methods or students' foundation. No matter what reasons, that information will give a chance to allow teachers to think and fix the problems.

\section{(2) Even wrong, still be welcomed}

Students should be encouraged to answer questions while class is being instructed. But their responses may be incorrect. If so, teachers should not blame them for lack of understanding, and still need to encourage them to bravely respond to the class. If other students mocked them, teachers should stop such disrespectful behaviors.

\section{(3) Asking after thinking}

Someone said:"Asking a question is often more important than solving a problem, because the solution may be just a mathematical or experimental skill." Questioning is a 
process of thinking. Like to question means like to think. Teachers should encourage students to think before they ask, and also encourage them to write down questions and try to get the answers by themselves by reading books or asking others. And students who ask questions and challenge ideas should be respected by teachers and other students. Even if these questions and ideas seem to be naive or very simple.

\subsection{Other Aspects}

The key to successful learning lies in the attention, memory and interest of the learners themselves. These three qualities are not innate but can be trained. Teachers as instructional leaders, their role is to use their knowledge, missions and responsibilities to motivate and help students to impulse their learning interests, concentration and the retention of knowledge.

\subsubsection{Improving Students' learning interests and confidence}

Not every student is naturally interested in math. Interest and confidence can be cultivated and improved.

\section{(1) Imagery teaching and edutainment}

Imagery teaching can be a good way to stimulate students' interests and let them easily remember abstract concepts or procedures. For example, for 2nd graders, they can't possibly understand the strict definitions of $y$-axis and $x$-axis, but teachers can say:" $y$-axis just likes playing yo-yo, up and down, $x$-axis is side to side." It is very pictorial so that students easily understand and remember. For 3rd grade, adding/subtracting two fractions with unlike denominators, they need to be reduced to the same denominator. The method is called the Butterfly Method which is very intuitive. Students feel easy to command and apply it.

Learning through playing is a good approach to stimulate students' participation especially when they are confused or run out of ideas. For instance, when 1st graders learn how to use a number line to add and subtract, if they are confused about the direction: add, go right; subtract, go left, teachers can ask them to jump to the right or left. For $5+3$, ask students first to locate the position of 5 on the number line, then turn right to jump three times to get 8 . For $5-3$, ask them to find the number 5 , then turn left to jump three times to get the result 3 .

\section{(2) Mathematics contest and confidence}

"Taking competitive, timed tests in elementary and middle schools are great practice for the standardized tests, kids will inevitably take in high school like the SAT, ACT and AP tests." 11 Math contests, even class level or grade level, will be able to stimulate students' participation and interests in learning math, boost their confidence and increase the courage of overcoming difficulties. Before contests, students need to do preparation by taking their spare time after school. It is a very good chance to motivate them to learn at home, they learn for their honor. By the opportunity of a small math competition, they are encouraged to memorize basic facts and practice basic arithmetic skills. It is a very good chance to inspire their math interest and confidence. This kind of math game can be held at any time when necessary and it is low cost.

Besides the math contests can take place in the school scope, also can be held in the level of several schools as a union. The representatives of each school will be selected to attend the math. They will be trained before the match.

There are many benefits of math contests. First of all, no matter any level of competition requires students to learn to deal with success and failure, and lets them realize that excellent performance takes practice and hard work. The results of the contests can help teachers to know more about 
their students in interest, fluency and knowledge retention. Secondly, contests are a good stimulation for students to develop their enthusiasm in math learning, at the same time to encourage them to value intellectual pursuits. Thirdly, an inter-school math competition helps to strengthen the teaching communication between schools. The winners can be good examples and incentives for other students who would like to improve themselves. And the students who have common interests can come together by the opportunities of competitions, form their own community in which they will find friendship, inspiration, and encouragement to a far greater degree than most of these students can find in the regular classroom.

All in all, the significance of math competitions is positive, no matter any level of math contest, it is a skill building opportunity for students that can help them enhance their learning ability and productivity.

For getting above benefits, the contents of contests should be well designed and distributed, except emphasizing skills, also developing the ability to think about and solve complex problems, and not too easy, not too hard. For class level, the purpose of contests is to remember the basic operation facts such as fact families of addition and subtraction, multiplication charts. For grade level and school level, if the contest is too easy, it can be misleading, running the risk of encouraging students to overvalue their math abilities. If too hard, it will discourage them and stifle their interest.

\subsubsection{Mental Calculation}

For improving students' math interests and confidence, a very simple method is to encourage students to count in their heads instead of counting in their fingers or something else. For example, 1st graders should be motivated to remember the addition chart within 10 , subtraction chart within 20, and recognize the rules of "make 10 " by addition or subtraction, double fact and its reverse operation. For 2nd grade and above, teachers should teach students some rapid calculations ${ }^{12}$ and inspire them to practice. For improving arithmetic skill, operation properties such as commutative, associative, distributive, identity are very important, students need to command.

\subsubsection{Mnemonics and concentration}

Not everyone was born with a good memory and concentration which are required training ${ }^{13,14}$.

(1) Improving memory by simple mnemonics Memory and understanding are complementary to each other. A good memory will be helpful to the retention and understanding of the knowledge, and at the same time to improve the learning efficiency. If students only rely on natural, incidental or unconscious memory in learning, their learning capacity can't be improved to the expected point. Their intentional memory needs to be developed. So teachers can intentionally consider passing on some simple mnemonics or try to develop students' memory while transferring knowledge. The simplest way is to encourage students to try to recite and memorize useful information or do rote memory. When students get used to remembering learning materials, their memory will naturally be improved. Another way is to build mnemonic imagery to the knowledge to impress students. For example, for kindergarteners being able to remember the numbers 0 9 more easily, teachers can show them pictures (also can make up some fun stories by connecting a number with the corresponding picture): 1 and a tree, 2 and a duck, 3 and an ear, 4 and a flag, 5 and a hook, 6 and a spoon, 7 and a cane or sickle, 8 and a bicycle or gourd, 9 and a tadpole. 
In addition, teachers need to know some characteristics of children's memory ${ }^{15}$, teach them some simple mnemonics ${ }^{16,17,18}$ such as rhyme method, characteristic memory method, categorization memory method, associative memory method, chart memory method. It will improve students' retention ability and intelligence development.

\section{(2) Improving concentration by attention training}

There is a close relationship between memory and concentration. Learning effectiveness will not be increased by good memory with lack of attention or by high concentration with bad memory. For many students, the biggest obstacle that affects the learning effect is lack of concentration which can be shown in many ways such as playing around the desk, no attention in listening and doing worksheets, easily distracted by neighboring students or any tiny noise, sensitive to the teacher's accent, changing behaviors because of changing teachers. Attention problems affect the learning efficiency and interest as well as increase the difficulties in classroom management and school education management.

For teachers, maintaining students' attention is a skill and not easy, which needs to be learned ${ }^{19}$. Students' capacity to concentrate is highly dependent on changes to the environment and within themselves (noise, stress, worries, tiredness, disruptive thoughts, etc). Teachers need to care about students' (individual or the whole class) concentration characteristics, design and implement some targeted attention training. Barry Schwartz argued 19:" If students are catered to short attention spans by offering materials that can be managed with short attention spans, the skill will not develop." A very simple method of attention training is the Schulte Table
Game, which can be used during math class, spent about 5 minutes. It is simple, time and cost economic, and can bring fun and relaxation to students. Another method is students are required to meditate in the company of music within 10 minutes, which also helps students to rest their brains and improve their concentration.

\subsubsection{Self-discipline, persistence and belief}

In fact, learning efficiency is more related to individual traits than concentration, memory and interest. Self-discipline, perseverance and strong belief (confidence) are three important qualities. Without self-discipline, learning can't hold on. Without persistence, dreams can't come true. To be successful, all three should be together. These qualities are not innate, but can be trained and learnt. From Kindergarten on, students should be taught about the importance of selfdiscipline, confidence, persistence, and courage to conquer difficulties by telling them fairytale stories or true stories no matter whether the figures are famous or ordinary, set some good examples for them as they can learn from or be influenced. Students should realize how important they are for their family, teachers, class, school and the communities, settle down their goals, and daily do some good things for helping themselves, others and improving the communities.

As long as students' learning enthusiasm, selfdiscipline and consciousness are stimulated, classroom management will not be hard, and the significant increase of learning efficacy will be possible.

\subsubsection{How students learn}

In the age of knowledge explosion, the goal of education has shifted from "what" students should learn to "how" they learn, developing students' learning skills, critical thinking, problem solving and communication skills are more 
important than purely acquiring academic knowledge ${ }^{6}$.

In order to develop students' mathematical identities, give students more confidence in their capacity to learn and to make sense of mathematics, it is necessary that teachers tell or recommend students to read some stories of mathematicians, or communicate students with their own learning experiences even failing experiences and learning techniques including teachers' unique and effective memorizing methods.

\section{Suggestions on Teaching Management}

Learning is not only a thing of teachers and students, but also a matter of school management and parents/guardians, which requires the support and close coordination from school administrators and families. Here are some suggestions for school teaching management.

(1) Motivating students to develop good habits

Good habits in behaviors, in learning, in self-confidence, in persistence are not born, they are made. To make them, family is important, schooling is even more important. School administrators should develop some training programs in forming students' good habits, which are implemented at the beginning, mid-term and the end of a semester, and checked at the midterm and the end of the semester. In the programs, some special educational lectures are necessary to set good examples by touching stories and deeds, to rectify and reflect on their own misbehavior by telling them what are acceptable behaviors (e.g., love, respect, patience, tolerance), to set small goals for improving their learning, behavior and the school community, etc. Under the unified supervision organized by school, to let students perceive some people/something always there to drive them forward makes them feel as if they've promised them to endure what lies ahead.

\section{(2) Reinforcing attention management and training}

In some sense, the management of student behavior is actually the management of learning interest and attention management. On the one hand, teachers and schools should make efforts to generate students' learning interest and enthusiasm. On the other hand, attention training should be brought into schools and classrooms by inviting experts to give students attention training on a regular or irregular basis.

\section{(3) Getting supports from family}

Schools should work hard to get parents' support to their children and school as well as teachers in supervising or urging their child/children to study at home: reading, doing homework or other activities that are good for mental and physical health including reading in a nearby library or helping parents to do some house work or the communities. In a year, more than two thirds of the time students stay at home, it is very important to form students' learning habits after school.

\section{(4) Teachers' training and professional de- velopment}

The sustained professional development of teachers is essential to the classroom effect ${ }^{2}$. The executive department of education should provide teachers the opportunities (time and space) to attend demonstration classes, teaching seminars, and to do teaching research. Teachers also need collaboration, mentoring and feedback, and are allowed to do teaching experiments, otherwise the professional development will be only an idea but will not be put into practice, the classroom effect will be difficult to be enhanced. 


\section{Conclusion}

Mathematics learning emphasizes foundation. The role of teachers is to help children to lay a good foundation of learning ability. Teaching is not easy because teachers undertake crucial responsibility for cultivating generations and generations who carry forward the development of society and human civilization. Yet the mission of teachers is glory. Finishing the requirements specified in the syllabus should not be the only mission for teachers, on the one hand, who should learn advanced and effective teaching modes while implementing teaching, on the other hand, who should know of students, carry out educational principles and apply advanced teaching methods according to their students' nature.

Education authorities and parents should give enough support for teachers to fulfill their mission.

\section{References}

1. Glenda Anthony, Margaret Walshaw. Effective Pedagogy in Mathematics. Educational Practices Series-19. UNESCO International Bureau of Education. 2009. Pages 32.

2. Barbara Oakley. A Mind For Numbers: How to Excel at Math and Science (Even If You Flunked Algebra)M. Tarcher Perigee. 2014.

3. Rohrer, D., Dedrick, R. F., Hartwig, M. K., \& Cheung, C.-N. (2020). A randomized controlled trial of interleaved mathematics practice. Journal of Educational Psychology, 112, 40-52.

4. Rohrer, D., Dedrick, R. F., \& Stershic, S. (2015). Interleaved practice improves mathematics learning. Journal of Educational Psychology, 107(3), 900-908.

5. Sean H. K. Kang. Spaced Repetition Promotes Efficient and Effective Learning: Policy Implications for Instruction. Policy Insights from the Behavioral and Brain Sciences 2016, 3(1) 12-19.

https://escipub.com/american-journal-of-educational-research-and-reviews/
6. Jensen, B., Hunter, A., Sonnemann, J., \& Burns, T. (2012). Catching up: Learning from the best school systems in East Asia. Grattan Institute.

7. Nisbet $\mathrm{S}$. Teaching mathematics for understanding J. Steadfast Press, 2010. pp: 1-12.

8. Doug Rohrer, Robert F. Dedrick, etl al.. A Randomized Controlled Trial of Interleaved Mathematics Practice J. Journal of Educational Psychology, 112(1), 40-52.

9. Rohrer $\mathrm{D}$, Taylor $\mathrm{K}$. The effects of overlearning and distributed practise on the retention of mathematics knowledge J. 2006, 20(9):1209-1224..

10. Stylianides A J , Stylianides G J . Learning Mathematics with Understanding: A Critical Consideration of the Learning Principle in the Principles and Standards for School Mathematics J. Montana Mathematics Enthusiast, 2007. 14(1), pp: 103-114.

11. Richard Rusczyk. The Pros and Cons of Math Competitions. SEPTEMBER 15, 2016. https://artofproblemsolving.com/news/articles/pros-cons-math-competitions

12. Gerard W. Kelly. Short-cut mathM. Dover Publications, April 1984.

13. Hermann Ebbinghaus (1885), Translated by Henry A. Ruger \& Clara E. Bussenius (1913). Memory: A Contribution to Experimental Psychology. https://psychclassics.yorku.ca/Ebbinghaus/index.htm

14. Stina Söderqvist and Sissela Bergman Nutley. Working Memory Training is Associated with Long Term Attainments in Math and ReadingJ. Frontiers in Psychology, 2015, 6(118):1711.

15. Gathercole S E, Lamont E, Alloway T P . Working Memory in the ClassroomJ. Educational Research \& Reviews, 2006, 1(5):382-385.

16. Alexandra Piacenza. 10 Mnemonic Devices That Every Elementary Schooler Will Remember. December

24 , 2014. 
https://www.noodle.com/articles/10-mnemonic-

devices-that-every-elementary-schooler-will-re-

member

17. Nidhi1Suman. Use of Mnemonics for Teaching Mathematics at the Primary Level J. The International Journal of Indian Psychology. 2016: 3(2),pp: 51-57.

18. Kathy DeLashmutt. A Study of the Role of Mnemonics in Learning Mathematics. July, 2007. https://digitalcommons.unl.edu/cgi/viewcontent.cgi?article $=1006 \&$ context $=$ mathmidsumma-

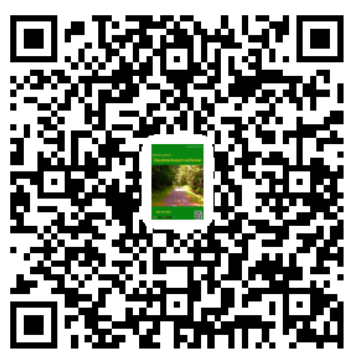
tive

19. BARRY SCHWARTZ. Attention Must Be Paid! Schools need to teach students to maintain attention, not cater to short-attention spans. SEPT 23, 2013 2:40 PM. https://slate.com/ human-interest/2013/09/paying-attention-is-a-skill-schoolsneed-to-teach-it.html 